\title{
O uso de parafraseamento na escrita pelos surdos
}

\section{The Use of Paraphrases in the Writing of the Deaf}

Wagner Teobaldo Lopes de Andrade

Universidade Federal da Paraíba (UFPB), João Pessoa, Paraíba, Brasil.

wagner_teobaldo@yahoo.com.br

Marígia Ana de Moura Aguiar

Universidade Federal de Pernambuco (UFPE), Recife, Pernambuco, Brasil.

marigia.aguiar@gmail.com

Francisco Madeiro

Universidade Católica de Pernambuco (UNICAP), Recife, Pernambuco, Brasil. madeiro@dei.unicap.br

Resumo: Os surdos têm dificuldade em desenvolver a oralidade, e a escrita apresenta-se como uma importante forma de comunicação desses sujeitos. Em se tratando de escrita, as marcas de oralidade estão diretamente relacionadas à coesão textual. Este estudo objetivou investigar a ocorrência de parafraseamentos, uma das principais marcas de oralidade, na escrita de surdos. Surdos oralizados e não-oralizados, além de ouvintes, responderam a um questionário e tiveram sua escrita analisada quantitativa e qualitativamente. Foi verificada a realização de parafraseamentos pelos surdos oralizados e ouvintes. Conclui-se que a relação oralidade/escrita ocorre apenas nos sujeitos que possuem oralidade (surdos oralizados e ouvintes).

Palavras-chave: Surdez; Oralidade; Língua de Sinais; Escrita. 
Abstract: The deaf have difficulty in developing speech and written language plays an important role in their communication. As for written language, oral cues exert a strong role in textual cohesion. This research aimed to investigate the occurrence of paraphrases, one of the main oral cues known in the literature, in the writing of the deaf. Oralized deaf individuals, non-oralized-deaf individuals and listeners answered a questionnaire in order to have the oral marks analyzed both on quantitative and qualitative grounds. The results showed the use of paraphrases by oralized-deaf individuals and listeners. It was concluded that speaking/writing relation occurs only in people who develop orality (oralized-deaf individuals and listeners).

Keywords: Deafness; Orality; Sign Language; Writing.

\section{Introdução}

O mundo dos surdos não permite a percepção dos sons da comunicação sem o uso da tecnologia, o que dificulta ou, muitas vezes, impossibilita o falar. Mas a comunicação natural existe através da língua de sinais, uma linguagem diferente, feita com as mãos e o corpo.

A dificuldade dos surdos em aprender a ler e escrever em língua portuguesa tem explicitamente chamado a atenção dos educadores. Hoje, com a concepção de língua de sinais como primeira língua para a população surda e instrumento de acesso ao conhecimento do mundo, a modalidade escrita assume o papel de alternativa à instrução formal e uma das fontes de conhecimento da cultura ouvinte, na qual o surdo também se insere.

Ouve-se muito, principalmente por parte dos pais de crianças surdas, que as dificuldades de aprendizagem, especialmente da escrita (na língua padrão do país), são um problema secundário em relação à aquisição da linguagem oral. Isso, no entanto, pode tomar grandes proporções se tivermos em mente que uma criança surda, além de apresentar grandes dificuldades ou, algumas vezes, não desenvolver a fala, aprende a ler apenas pequenos textos, frases simples e apresenta inúmeras complicações na escola.

As habilidades de escrita são um importante complemento para a língua de sinais e para a aquisição do conhecimento dos estudantes surdos. É quase impossível imaginar alguém que se oponha à afirmação de que todo cidadão tem o direito de participar da vida social, política e econômica da nação. Da mesma maneira, todos parecem partilhar 
o sentimento de que é responsabilidade da escola dar ao cidadão o instrumental mínimo para que ele exerça seu direito de avançar profissional e socialmente.

Tendo em vista a dificuldade que os surdos apresentam em desenvolver a língua oral, o presente estudo parte da constatação da grande importância da escrita para esses sujeitos. Além de ser o continuum oralidade-escrita um agente determinante e transformador da língua (CALADO, 2004) e esta ser, em sua modalidade oral, muitas vezes, de difícil utilização pelos surdos, a escrita na língua padrão do país, como já foi referido, torna-se um instrumento importante para a inserção desse indivíduo na sociedade e um meio importante de registro de ideias e pensamentos (QUADROS, 1993).

A relação entre a oralidade e a escrita é consensual na literatura; no entanto, até o presente momento, não foram encontrados estudos que identifiquem essa relação nos surdos, sujeitos que não possuem acesso natural à modalidade oral da língua.

Dessa forma, a pergunta norteadora deste estudo é: o fato de ser oralizado faz com que o surdo utilize mais marcas de oralidade, especialmente, parafraseamentos, na sua escrita (tenha um texto mais coeso) do que o surdo não-oralizado, mesmo não utilizando a língua oral de forma corrente?

Sabendo que os surdos podem apresentar seu funcionamento linguístico marcado pelo uso exclusivo da oralidade, uso exclusivo da língua de sinais ou uso de ambas, o objetivo deste estudo foi investigar a ocorrência de parafraseamentos na escrita em língua portuguesa de estudantes surdos e comparar os achados aos de ouvintes de mesmo grau de escolaridade.

\section{Fundamentação teórica}

Este trabalho assume como pressuposto o conceito apresentado por Marcuschi $(2001,2005)$ de que a língua é muito mais um conjunto de práticas discursivas do que somente uma série de regras ou um sistema de formas simbólicas. Nessa perspectiva, a língua se manifesta e funciona como atividade oral e como atividade escrita.

Para Marcuschi (1995, 2004) e Cavalcante e Marcuschi (2005), a fala e a escrita, enquanto práticas interativas e complementares no contexto das práticas sociais e culturais, não devem ser tratadas de 
forma estanque e dicotômica. Marcuschi (2004) destaca que a oralidade e a escrita são práticas e usos da língua com características próprias que permitem a construção de textos coesos e coerentes, a elaboração de raciocínios abstratos e exposições formais e informais, variações estilísticas, sociais e dialetais, entre outras. O uso da língua, segundo Marcuschi (2005), ocorre num continuum de relações entre modalidades, gêneros textuais e contextos socioculturais.

Apesar de se considerar a existência de diferenças entre o falar e o escrever, neste trabalho, foi considerada a perspectiva de análise de Collins e Michaels (1991) e Marcuschi (1998, 2004), segundo os quais a fala e a escrita não formam dois extremos, mas um continuum distribuído numa escala de parâmetros empiricamente detectáveis, cuja identificação permite a inferência de que as características presentes na fala podem estar presentificadas também na escrita.

Na visão de Marcuschi (1995), é mais razoável olhar a relação entre a fala e a escrita sob o aspecto das características de cada modalidade do que apenas das diferenças. Desta forma, as modalidades falada e escrita da língua devem ser analisadas em função das suas relações de semelhança e diferença dentro de um quadro de categorias da mesma ordem de observação de fenômenos, pois alguns desses fenômenos atribuídos à fala ou à escrita não são próprios de uma ou outra, mas propriedades gerais da própria linguagem enquanto fenômeno social (MARCUSCHI, 1998, 2004, 2005).

A partir da proposta marcuschiana de que a relação entre a fala e a escrita se funda num continuum, é de se esperar que características de uma modalidade linguística estejam presentes na outra. Dessa forma, tendo em vista a importância da coesão textual para os surdos pela dificuldade que possuem em desenvolver a língua oral e, consequentemente, produzir escrita de textos na língua padrão, as marcas de oralidade, por estarem diretamente relacionadas à coesão do texto, podem ser um elemento auxiliar do processo de organização textual, proporcionando maior coesividade ao texto produzido pelo surdo.

Segundo Marcuschi (2002), as principais marcas de oralidade são os marcadores discursivos, a repetição, a correção e o parafraseamento. Neste trabalho, detivemo-nos na análise dos parafraseamentos.

De acordo com Gülich e Kotschi (1987, apudFÁVERO;ANDRADE; AQUINO, 2006), na paráfrase, há a especificação ou generalização de um termo, determinando uma progressão textual e gerando novos sentidos. 
O parafraseamento é uma estratégia realizada pelos interlocutores para produzirem dinamicamente referências textuais, levados pelos propósitos da ação interativa. Tannen (1985) afirma que, por natureza, a paráfrase é um tipo de repetição.

Hilgert (2006) define o parafraseamento como uma estratégia de construção textual que se situa entre as atividades de reformulação, em que novos enunciados remetem a anteriores, modificando-os parcial ou totalmente, mantendo uma relação de equivalência semântica entre os enunciados e retomando, geralmente, de forma resumida, o conteúdo anteriormente exposto (JUBRAN et al., 1996).

Como já foi mencionado, o parafraseamento sempre implica algum deslocamento de sentido, com uma relação de equivalência semântica entre o enunciado-origem ou matriz e outro enunciado linguístico (a paráfrase) que o reformula (HILGERT, 1997). Segundo Fuchs (1982, apud KOCH et al., 2002, p. 139), a paráfrase implica uma atividade efetiva de reelaboração, pela qual o locutor "bem ou mal, na totalidade ou em parte, fielmente ou não, restaura o conteúdo de um texto-fonte, primitivo, num texto derivado".

Além disso, segundo Gülich e Kotschi (1983, apud HILGERT, 2006), existe a relação de predicação de identidade, através da qual dois enunciados são produzidos e encadeados de tal forma que podem ser compreendidos como idênticos.

Quanto à atuação na estruturação textual, Hilgert (2006) afirma que as paráfrases não-adjacentes mantêm a centração tópica, enquanto as paráfrases adjacentes realizam a aproximação lexical no processo de escolha do termo mais adequado para os propósitos comunicativos.

Para Hilgert (1997), na passagem da matriz para a paráfrase, manifestam-se dois tipos de movimentos semânticos: a especificação e a generalização. A especificação (condensação ou redução parafrástica) ocorre quando a abrangência da matriz é maior do que a da paráfrase, ou seja, o movimento semântico vai do geral para o específico. $\mathrm{Na}$ generalização (expansão parafrástica), acontece o contrário: a abrangência da matriz é menor do que a da paráfrase, em um movimento semântico que vai do específico para o geral.

O autor destaca, ainda, que, além desses movimentos semânticos, a paráfrase pode manter a mesma dimensão formal da matriz (paralelismo parafrástico), registrando-se uma simples variação lexical, o movimento semântico paralelo. 
Sabendo que, em função da falta de feedback auditivo, o surdo pode apresentar alteração no desenvolvimento fonológico, vocabulário receptivo e expressivo, sintaxe e morfologia, além da compreensão (SANTOS; NAVAS, 2002), a escrita, especialmente, a coesão textual, se configura em uma habilidade imprescindível para a comunicação desses sujeitos. A paráfrase, nesse contexto, apresenta-se como uma das estratégias linguísticas de que pode dispor o sujeito para promover maior coesão no seu texto.

A literatura em Audiologia Educacional e Educação Especial destaca, entre as filosofias para a educação do surdo, o oralismo e o bilinguismo, que tem como objetivo proporcionar o desenvolvimento pleno de suas capacidades (LACERDA, 1998).

A corrente oralista tem como pressuposto que as crianças surdas devem desenvolver como primeira forma comunicativa a língua oral (HARRISON; LODI; MOURA, 1997), enfatizando essa língua em termos terapêuticos (COUTO-LENZI, 1997).

Segundo Perdoncini (1996), o oralismo apresenta um profundo desejo de sempre pensar nas crianças surdas em termos de audição. A filosofia oralista tem como objetivo fazer a reabilitação da criança surda em direção à normalidade e é considerada uma imposição social de uma maioria linguística (os ouvintes) sobre uma minoria linguística (os surdos) sem expressão diante da comunidade ouvinte (SÁNCHEZ, 1990; LANE, 1992; FERREIRA-BRITO, 1993; SKLIAR; MASSONE; VEINBERG, 1995; BUENO, 1998).

Perdoncini e Couto-Lenzi (1996) afirmam que às crianças surdas falta o sentido auditivo e a função auditiva. Por isso, os estudiosos e profissionais que realizam o oralismo costumam chamar as crianças de "deficientes auditivas" ou, simplesmente, "deficientes". A surdez, de forma semelhante, é chamada de "deficiência auditiva". Nessa concepção, a criança não é vista como um surdo, mas um sujeito que pode perceber sons (PERDONCINI, 1996). Essa perspectiva encontra base no fato de que a grande maioria das crianças surdas apresenta algum tipo de resíduo auditivo, dificilmente utilizado naturalmente. Segundo CoutoLenzi (1997), os surdos de grau severo e profundo têm audição residual aproveitável, o que significa a possibilidade de atingir os sons da fala. Esse potencial auditivo, no entanto, é otimizado através da protetização auditiva e de uma adequada estimulação terapêutica (ou educação auditiva) em direção à fala. 
No entanto, os resultados dessas tentativas de oralização se mostraram frágeis ao longos dos anos. Considerando, então, que a maior parte das crianças com surdez profunda adquire apenas fragmentos linguísticos através da linguagem oral, um número cada vez maior de profissionais defende o modelo de educação bilíngue, que se diferencia do modelo oralista por considerar o canal viso-gestual como fundamentalmente importante para a aquisição da linguagem da criança surda (LACERDA, 1998).

Essa proposta pressupõe que os surdos desenvolvam competência em duas línguas: a língua padrão do país (no caso do Brasil, o português) e a língua de sinais, que é uma língua de modalidade viso-gestual (SANTOS; DIAS, 1998), multicanal (uso da face, olhos, cabeça, corpo e mãos) (FELIPE, 1988) e um sistema linguístico independente do sistema de línguas orais (QUADROS, 1997), ao qual se equivale em qualidade e importância (CICCONE, 1996).

Para os defensores dessa corrente, a língua de sinais é importante para o surdo, permitindo-lhe um desenvolvimento de linguagem satisfatório em termos de efetividade comunicativa (QUADROS, 1997; SALLES et al., 2004), assim como a exposição à língua portuguesa promove o desenvolvimento linguístico do ouvinte. A língua de sinais, por outro lado, passa a atuar como um estigma, na medida em que evidencia a surdez.

O bilinguismo permite duas formas de implantação (dependendo da segunda língua utilizada pelo surdo), coincidentes apenas quanto à primeira língua: a língua de sinais (GOLDFELD, 2002; SOUZA, 1998; FERNANDES, 2003). A segunda língua, no caso do Brasil, corresponde à língua portuguesa (FERNANDES, 1990), seja na modalidade oral e escrita ou apenas escrita.

A língua de sinais para os surdos, assim como o português falado para os ouvintes, fornecerá todo o aparato linguístico-cognitivo necessário à utilização de estratégias de interpretação e produção de textos escritos (BRASIL, 1997). O seu objetivo é que a criança surda possa ter um desenvolvimento linguístico-cognitivo adequado, assim como acontece com a criança ouvinte, e que possa desenvolver uma relação harmoniosa também com ouvintes, tendo acesso a duas línguas: a de sinais e a do grupo majoritário (LACERDA, 2000).

Dessa forma, posicionamo-nos favoravelmente ao bilinguismo como filosofia educacional para o desenvolvimento da linguagem do 
surdo, assim como à perspectiva de análise da sua escrita sob o ponto de vista da coesão e da coerência, sem nos prendermos a possíveis equívocos que os sujeitos possam apresentar na área da morfologia ou da sintaxe.

Acreditamos que essa postura favorecerá o desenvolvimento da escrita do surdo, pois teremos como foco o conteúdo e não apenas a forma, que, apesar de importante, não deve ser priorizada no processo de escolarização desses sujeitos.

\section{Método}

O presente estudo foi realizado em uma escola da rede pública da cidade de Recife/PE, onde ocorre o ensino integrado entre surdos e ouvintes. Na escola, existiam, no ano de 2006, 34 alunos surdos nas turmas diurnas e noturnas do Ensino Médio. Intérpretes de língua de sinais atuam na sala de aula, fazendo a interpretação dessa língua para o português e vice-versa e facilitando, assim, a comunicação entre surdos e ouvintes.

Participaram do estudo 45 sujeitos de ambos os sexos, entre 17 e 38 anos de idade, estudantes do Ensino Médio. Destes, 15 são ouvintes e 30 são surdos bilíngues, que apresentam surdez de grau severo ou profundo bilateral e pré-lingual (antes dos três anos, segundo MONREAL et al., 1995). Dos 30 participantes surdos, 15 são oralizados e 15 nãooralizados.

Os sujeitos da pesquisa foram solicitados a responder algumas perguntas de natureza pessoal a respeito da surdez (uso de prótese auditiva e realização de terapia fonoaudiológica para o desenvolvimento da linguagem oral e/ou escrita) e a responder a um questionário contendo seis perguntas acerca do seu dia a dia na escola. A ajuda dos intérpretes da escola foi solicitada sempre que houve o surgimento de dúvidas, especialmente com relação ao que o surdo queria expressar. Esses profissionais, no entanto, não interferiram no processo de escrita do surdo.

Os participantes ouvintes responderam a um questionário similar com conteúdo análogo e mesma quantidade de questões, adaptadas ao fato de não serem surdos.

Anteriormente à realização da coleta dos dados, o projeto de pesquisa foi aprovado pelo Comitê de Ética em Pesquisa com Seres Humanos da Universidade Católica de Pernambuco. 
Os dados foram analisados em função da ocorrência de parafraseamentos na escrita entre os grupos, através do teste estatístico de T-student, utilizado para realizar comparações de médias entre dois grupos (surdos oralizados x ouvintes), pelo fato de não ter sido verificada a ocorrência da marca de oralidade em questão na escrita dos surdos não-oralizados.

A diferença entre as médias dos grupos foi considerada estatisticamente significante quando o p-valor fornecido pelo teste estatístico se mostrou menor ou igual a $0,05(\mathrm{p} \leq 0,05)$. O p-valor foi arredondado para até três casas decimais.

\section{Resultados e discussões}

Todos os surdos oralizados participantes do estudo já fizeram uso de prótese auditiva. O tempo de utilização do aparelho de amplificação sonora variou entre cinco e dezessete anos. Já entre os surdos nãooralizados, apenas oito afirmaram haver feito uso de prótese auditiva, com tempo de uso que variou entre um e seis anos. Alguns surdos, no entanto, não souberam precisar o tempo de utilização da prótese auditiva.

Dessa forma, mais surdos oralizados fazem ou fizeram uso de prótese auditiva em relação aos não-oralizados, além de ser o tempo de uso do equipamento, em geral, maior entre os oralizados. O menor tempo de utilização ou a não-utilização da prótese auditiva é compatível com o fato de os surdos não serem oralizados, pois, segundo Tye-Murray (1998), o não-uso do equipamento de amplificação sonora individual dificulta ou, muitas vezes, impossibilita o acesso à modalidade oral da língua. Podese inferir, ainda, que quanto menor o tempo de uso da prótese auditiva, menor é o contato do surdo com a língua oral e, consequentemente, menores serão suas habilidades linguísticas orais.

A terapia fonoaudiológica para o desenvolvimento da linguagem oral e/ou escrita é (foi) realizada por doze surdos oralizados, por um período de tempo que variou entre dois e doze anos. Entre os surdos não-oralizados, nenhum fazia fonoterapia no momento, enquanto nove afirmaram já a ter realizado anteriormente. O tempo de realização de terapia fonoaudiológica dos surdos não-oralizados variou de três meses a cinco anos. Alguns surdos oralizados e não-oralizados não souberam fornecer a informação referente ao tempo de realização da terapia. 
A terapia fonoaudiológica é um importante instrumento para o desenvolvimento e otimização das habilidades linguísticas orais e escritas do surdo (BELTRÁN e VILLALOBOS, 1998), o que torna natural a verificação de que, em relação aos surdos oralizados, um maior número de surdos não-oralizados nunca realizou fonoterapia, além de nenhum fazê-la no momento da coleta dos dados.

O fato de um maior número de surdos oralizados realizar ou ter realizado terapia fonoaudiológica e usar ou ter usado prótese auditiva em relação aos surdos não-oralizados permite a sugestão de que, possivelmente, aqueles sujeitos apresentam, de fato, habilidades linguísticas orais mais desenvolvidas que estes.

De acordo com a Tabela 1, percebe-se que o parafraseamento foi realizado em maior quantidade pelos ouvintes em relação aos surdos oralizados. Como já foi mencionado, não se verificou a ocorrência de parafraseamentos na escrita dos surdos não-oralizados, ou seja, esses sujeitos não manifestaram relação entre enunciados na sua escrita, um processo que acontece natural e corriqueiramente na fala.

Tendo em vista o fato de a quantidade máxima de paráfrases por sujeito ter sido quatro, os participantes tiveram a frequência de paráfrases classificada em baixa (quando produziram entre um e dois parafraseamentos) e alta frequência (quando a ocorrência foi de três a quatro parafraseamentos).

Pôde-se perceber, a partir da Tabela 2, que a ocorrência dessa marca de oralidade foi, predominantemente, de baixa frequência. Apenas um sujeito (surdo oralizado) realizou mais de duas paráfrases em sua produção escrita.

As paráfrases foram classificadas com relação ao tipo segundo Hilgert (1997, 2006) (Tabela 3). Mesmo sendo pequeno o número de surdos oralizados que realizaram parafraseamento, prevaleceu, nesse grupo, a especificação ou condensação parafrástica, enquanto um maior número de ouvintes realizou movimento semântico paralelo.

A generalização ou expansão parafrástica não foi produzida sequer por um participante da pesquisa. Hilgert (1997, 2006), em publicações que enfocam o parafraseamento na fala, afirma que as generalizações parafrásticas são as mais frequentes entre os três tipos, representando $56 \%$ dos movimentos semânticos realizados, o que vai de encontro aos achados deste estudo, focado na escrita. 
As especificações parafrásticas são, ainda segundo Hilgert (1997, 2006), as menos ocorrentes na fala, totalizando $18 \%$ dos parafraseamentos produzidos. Esse tipo de paráfrase, no entanto, prevaleceu no grupo de surdos oralizados, diferindo do autor citado, apesar de os estudos desse autor voltarem-se, como já foi citado, à produção do parafraseamento na linguagem oral.

A correlação estatística entre a ocorrência de parafraseamentos pelos surdos oralizados e ouvintes não mostrou diferença estatisticamente significante entre essas duas populações (Tabela 4). O p-valor $(0,818)$ mostra que a utilização de parafraseamento pelos dois grupos foi bastante próxima.

Tabela 1 - Distribuição quantitativa dos participantes segundo o uso de parafraseamentos

\begin{tabular}{c|c|c|c|c|c|c|c|c}
\hline \multirow{2}{*}{} & \multicolumn{2}{|c|}{ ORALIZADOS } & \multicolumn{2}{c|}{ NÃO-ORALIZADOS } & \multicolumn{2}{c|}{ OUVINTES } & \multicolumn{2}{c}{ TOTAL } \\
\cline { 2 - 9 } & $\boldsymbol{N}$ & $\%$ & $\boldsymbol{N}$ & $\%$ & $\boldsymbol{N}$ & $\%$ & $\boldsymbol{N}$ & $\%$ \\
\hline Sim & 3 & 20,00 & 0 & 0 & 5 & 33,33 & 8 & 17,78 \\
\hline Não & 12 & 80,00 & 15 & 100,00 & 10 & 66,67 & 37 & 82,22 \\
\hline Total & 15 & 100,00 & 15 & 100,00 & 15 & 100,00 & 45 & 100,00 \\
\hline
\end{tabular}

Tabela 2 - Distribuição quantitativa dos participantes segundo a frequência do parafraseamento

\begin{tabular}{c|c|c|c|c|c|c}
\hline \multirow{2}{*}{} & \multicolumn{2}{|c|}{ ORALIZADOS } & \multicolumn{2}{c|}{ OUVINTES } & \multicolumn{2}{c}{ TOTAL } \\
\cline { 2 - 7 } & $\boldsymbol{N}$ & $\%$ & $\boldsymbol{N}$ & $\%$ & $\boldsymbol{N}$ & $\%$ \\
\hline Baixa & 2 & 66,67 & 5 & 100,00 & 7 & 87,50 \\
\hline Alta & 1 & 33,33 & 0 & 0 & 1 & 12,50 \\
\hline Total & 3 & 100,00 & 5 & 100,00 & 8 & 100,00 \\
\hline
\end{tabular}


256 Revista de Estudos da Linguagem, Belo Horizonte, v.23, n.1, p. 245-260, 2015

Tabela 3 - Distribuição quantitativa dos parafraseamentos segundo o tipo

\begin{tabular}{c|c|c|c|c|c|c}
\hline \multirow{2}{*}{} & \multicolumn{2}{|c|}{ ORALIZADOS } & \multicolumn{2}{c|}{ OUVINTES } & \multicolumn{2}{c}{ TOTAL } \\
\cline { 2 - 7 } & $\boldsymbol{N}$ & $\%$ & $\boldsymbol{N}$ & $\%$ & $\boldsymbol{N}$ & $\%$ \\
\hline General. & 0 & 0,00 & 0 & 0,00 & 0 & 0,00 \\
\hline Especif. & 2 & 66,67 & 2 & 40,00 & 4 & 50,00 \\
\hline Paralel. & 1 & 33,33 & 3 & 60,00 & 4 & 50,00 \\
\hline Total & 3 & 100,00 & 5 & 100,00 & 8 & 100,00 \\
\hline
\end{tabular}

Legenda:

General. $=$ Generalização parafrástica

Especif. $=$ Especificação parafrástica

Paralel. $=$ Paralelismo parafrástico

Tabela 4 - Correlação estatística entre as médias de quantidade de parafraseamentos utilizada pelos surdos oralizados e ouvintes (Teste

T-student).

\begin{tabular}{c|c|c}
\hline & ORALIZADOS & OUVINTES \\
\hline Média & 0,333 & 0,4 \\
\hline p-valor & 0,818 & \\
\hline
\end{tabular}

\section{Conclusões}

A análise do material permite a conclusão de que os parafraseamentos se mostraram presentes na escrita dos surdos oralizados e ausentes entre os surdos não-oralizados participantes do estudo.

A ocorrência de parafraseamentos se deu em maior quantidade pelos ouvintes, seguidos pelos surdos oralizados. Apesar da pouca ocorrência de parafraseamentos nos dois grupos, verificou-se maior realização de especificação parafrástica entre os surdos oralizados e de paralelismo parafrástico entre os ouvintes.

Além disso, a correlação estatística entre a utilização de parafraseamento pelos surdos oralizados e pelos ouvintes mostrou que a média dos dois grupos foi parecida. 
Diante do exposto, sugere-se ocorrência do continuum oralidadeescrita nos surdos oralizados, assim como ocorre naturalmente nos ouvintes.

Este estudo sugere que, pelo fato de as marcas de oralidade constituírem um fator de coesão textual, o uso desses recursos pode se configurar em mais uma frente de trabalho com a escrita do surdo, especialmente o não-oralizado, a fim de estimular a coesão das produções desses sujeitos.

\section{Referências}

BELTRÁN, L.F.; VILLALOBOS, P.B. El niño sordo de edad preescolar: identificación, diagnostico y tratamiento - guía para padres, médicos y maestros. 2. ed. México: Trillas, 1998.

BRASIL. Ministério da Educação e do Desporto. Secretaria de Educação Especial. Programa de capacitação de recursos humanos do ensino fundamental: A educação dos surdos. v. II. Brasília: MEC/SEESP, 1997. BUENO, J. G. S. Surdez, linguagem e cultura. Cadernos CEDES, Campinas, v. 46, n. 19, p. 41-56, set. 1998.

CALADO, L. C. Variações linguísticas no contexto de escolas públicas: fatores intervenientes. 2004. 112 f. Dissertação (Mestrado em Ciências da Linguagem) - Universidade Católica de Pernambuco, Recife, 2004.

CAVALCANTE, M. C. B.; MARCUSCHI, B. Formas de observação da oralidade e da escrita em gêneros diversos. In: MARCUSCHI, L. A.; DIONÍSIO, A. P. Fala e escrita. Belo Horizonte: Autêntica, 2005. p. 123-143. CICCONE, M. M. C. Comunicação Total - introdução, estratégia, a pessoa surda. 2. ed. Rio de Janeiro: Cultura Médica, 1996.

COLLINS, J.; MICHAELS, S. A fala e a escrita: estratégias de discurso e aquisição da alfabetização. In: COOK-GUMPERZ, J. (Org.). $A$ construção social da alfabetização. Porto Alegre: Artes Médicas, 1991. p. 242-258.

COUTO-LENZI, A. Percepção da fala: teste. Rio de Janeiro: Timing, 1997. FÁVERO, L. L.; ANDRADE, M. L. C. V. O.; AQUINO, Z. G. O. Correção. In: JUBRAN, C. C. A. S.; KOCH, I. G. V. Gramática do português culto falado no Brasil. Campinas: UNICAMP, 2006. p. 255273. 
258 Revista de Estudos da Linguagem, Belo Horizonte, v.23, n.1, p. 245-260, 2015

FELIPE, T.A. O signo gestual-visual e sua estrutura frasal na lingua de sinais dos centros urbanos do Brasil (LSCB). 1988. 105 f. Dissertação (Mestrado em Linguística) - Universidade Federal de Pernambuco, Recife, 1988.

FERNANDES, E. Problemas lingüisticos e cognitivos dos surdos. Rio de Janeiro: Agir, 1990.

FERNANDES, E. Linguagem e surdez. Porto Alegre: Artmed, 2003.

FERREIRA-BRITO, L. Integração social \& educação de surdos. Rio de Janeiro: Babel, 1993.

GOLDFELD, M. A criança surda: linguagem e cognição numa perspectiva sócio-interacionista. 2. ed. São Paulo: Plexus, 2002.

HARRISON, K. M. P.; LODI, A. C. B.; MOURA, M. C. Escolas e escolhas: processo educacional dos surdos. In: LOPES FILHO, O. (Ed.). Tratado de Fonoaudiologia. São Paulo: Roca, 1997. p. 359-400.

HILGERT, J. G. As paráfrases na construção do texto falado: o caso das paráfrases em relação paradigmática com suas matrizes. In: $\mathrm{KOCH}$, I. G. V. (Org.). Gramática do português falado. 2. ed. v. 6. Campinas: UNICAMP/FAPESP, 1997. p. 131-147.

HILGERT, J. G. Parafraseamento. In: JUBRAN, C. C. A. S.; KOCH, I. G. V. Gramática do português culto falado no Brasil. Campinas: UNICAMP, 2006. p. 275-299.

JUBRAN, C. C. A. S. et al. Organização tópica da conversação. In: ILARI, R. (Org.). Gramática do português falado. 3. ed. v. 2. Campinas: UNICAMP, 1996. p. 351-375.

KOCH, I. G. V. et al. Aspectos do processamento do fluxo de informação no discurso oral dialogado. In: CASTILHO, A. T. (Org.). Gramática do português falado. 4. ed. v. 1. Campinas: UNICAMP, 2002. p. 121-154.

LACERDA, C. B. F. Um pouco da história das diferentes abordagens na educação de surdos. Cadernos CEDES, Campinas, v. 46, n. 19, p. 68-80, set. 1998.

LACERDA, C. B. F. A prática pedagógica mediada (também) pela língua de sinais: trabalhando com sujeitos surdos. Cadernos CEDES, Campinas, v. 50, n. 20, p. 70-83, abr. 2000.

LANE, H. A máscara da benevolência: a comunidade surda amordaçada.

Lisboa: Horizontes pedagógicos, 1992. 
MARCUSCHI, L. A. Contextualização e explicitude na relação entre fala e escrita. Encontro Nacional sobre Língua Falada e Ensino, 1, 1994, Maceió. Anais..., Maceió: UFAL, 1995. p. 27-48.

MARCUSCHI, L. A. Nove teses para uma reflexão sobre a valorização da fala no ensino da língua. Revista da ANPOLL, v. 4, n. 3, p. 325-332. 1998.

MARCUSCHI, L. A. Letramento e oralidade no contexto das práticas sociais e eventos comunicativos. In: SIGNORINI, I. et al. (Org.). Investigando a relação oral/escrito e as teorias do letramento. Campinas: Mercado das Letras, 2001. p. 23-74.

MARCUSCHI, L. A. A presença da repetição na fala e algumas perspectivas de tratamento. Investigações: Linguística e Teoria Literária, Recife, v. 2, p. 31-47, dez. 2002.

MARCUSCHI, L. A. Da fala para a escrita: atividades de retextualização. 5. ed. São Paulo: Cortez, 2004.

MARCUSCHI, L. A. Oralidade e letramento como práticas sociais. In: MARCUSCHI, L. A.; DIONÍSIO, A. P. Fala e escrita. Belo Horizonte: Autêntica, 2005. p. 31-55.

MONREAL, S. T. (Coord.) et al. Deficiencia auditiva: aspectos psicoevolutivos y educativos. Granada: Aljibe, 1995.

PERDONCINI, G. Prefácio. In: PERDONCINI, G.; COUTO-LENZI, A. Audição é o futuro da criança surda. Rio de Janeiro: Aipeda, 1996. p. 7-10.

QUADROS, R. M. Lingüística contrastiva - o ensino da língua escrita para surdos via língua de sinais. II Congresso Latino-Americano de Bilingüismo para Surdos. Rio de Janeiro, 1993.

QUADROS, R. M. Educação de surdos: a aquisição da linguagem. Porto Alegre: Artes Médicas, 1997.

PERDONCINI, G.; COUTO-LENZI, A. Audição é o futuro da criança surda. Rio de Janeiro: Aipeda, 1996.

SALLES, H. M. M. L. et al. Ensino de língua portuguesa para surdos: caminhos para a prática pedagógica. Brasília: MEC/SEESP, 2004.

SÁNCHEZ, C. M. La increíble y triste historia de la sordera. Caracas: CEPROSORD, 1990. 
SANTOS, L. H. M.; DIAS, M. G. B. B. Compreensão de textos em adolescentes surdos. Psicologia: teoria e pesquisa, Brasília, v. 14, n. 3 , p. 241-249, set./dez. 1998.

SANTOS, M. T. M.; NAVAS, A. L. G. P. Distúrbios de leitura e escrita. In: SANTOS, M. T. M.; NAVAS, A. L. G. P. (Org.). Distúrbios de leitura e escrita: teoria e prática. Barueri: Manole, 2002. p. $27-74$.

SKLIAR, C.; MASSONE, M.; VEINBERG, S. El acceso de los niños sordos al bilingüismo y al biculturalismo. Revista Infancia y Aprendizaje, Madrid, v. 2, n. 69/70, p. 85-100, 1995.

SOUZA, R. M. Língua de sinais e língua majoritária como produto de trabalho discursivo. Cadernos CEDES, Campinas, v. 46, n. 19, p. 57-67, set. 1998.

TANNEN, D. Repetition and variation as spontaneous formulaicity in conversation. Georgetown University, 1985 (mimeo).

TYE-MURRAY, N. Foundations of Aural Rehabilitation: Children, Adults and their Family Members. San Diego: Singular, 1998. 